\title{
Sulfidation of Single-Phase Oxide on Copper and as Powder Studied Using Soft X-Ray Spectroscopy
}

\author{
P. T. Kristiansen, ${ }^{\mathrm{a}, \mathrm{b}}$ F. Massel, ${ }^{\mathrm{a}}$ L. Werme, ${ }^{\mathrm{a}}$ C. Lilja, ${ }^{\mathrm{c}}$ and L.-C. Duda ${ }^{\mathrm{a}, \mathrm{z}}$ \\ ${ }^{a}$ Department of Physics and Astronomy, Division of Molecular and Condensed Matter Physics, Uppsala University, \\ S-751 20 Uppsala, Sweden \\ ${ }^{b}$ Abteilung Anorganische Chemie, Fritz-Haber-Institut der Max-Planck-Gesellschaft, D-14195 Berlin, Germany \\ ${ }^{c}$ Swedish Nuclear Fuel and Waste Management Co, SE-101 24 Stockholm, Sweden
}

\begin{abstract}
The high corrosion resistance of copper is a key feature in the design of copper-lined canisters that will be utilized to protect people and the environment from dangers of spent nuclear fuel far into the future. Our present study sheds light on the effects that sulfide ions in otherwise relatively benign anoxic groundwater may have on the copper of the container material. Using soft X-ray spectroscopy, we have studied the chemistry of the transformation of single-phase copper oxide cover layers (cuprite, tenorite, paratacamite) as well as single-phase oxide powders (paratacamite and malachite) when exposed to aqueous sulfide solutions. While X-ray diffraction shows that the main bulk of the oxides are nearly unaffected, $\mathrm{Cu}$ L-edge absorption spectroscopy shows that a cover layer of about 100 $\mathrm{nm}$ thickness on the metal substrate is transformed from $\mathrm{Cu}(\mathrm{II})$ - to $\mathrm{Cu}(\mathrm{I})$-species. By contrast, paratacamite and malachite powders exposed to the same kind of aqueous sulfide solutions show much less transformation to $\mathrm{Cu}(\mathrm{I})$-species. We conclude that the main mechanism for reduction of $\mathrm{Cu}$ (II) on copper is the comproportionation reaction between divalent copper ions from the covering oxide and the underlying metallic copper atoms to form monovalent copper ions. By contrast, the absence of metallic copper inhibits this mechanism in the powders.

(c) The Author(s) 2015. Published by ECS. This is an open access article distributed under the terms of the Creative Commons Attribution 4.0 License (CC BY, http://creativecommons.org/licenses/by/4.0/), which permits unrestricted reuse of the work in any medium, provided the original work is properly cited. [DOI: 10.1149/2.0801514jes] All rights reserved.
\end{abstract}

Manuscript submitted May 19, 2015; revised manuscript received September 16, 2015. Published October 23, 2015.

Sweden and Finland have selected copper as the outer material for containers for disposal of spent nuclear fuel from nuclear reactors. Copper is also being considered in Canada as a possible container material. This choice is based on thermodynamic stability of this metal in the anoxic saline groundwaters that are anticipated to prevail in the waste repositories of these countries. The only potentially available oxidant at the depth of the repository will be aqueous sulfide; the sulfide source being dissolution of minerals or microbial activity. The sulfide levels are expected to be relatively low. At the Swedish repository site at Forsmark the measured sulfide concentrations have been measured to be generally below $1.3 \cdot 10^{-5} \mathrm{M}$. $^{1}$

Even though the undisturbed deep groundwaters are oxygen-free, oxygen will of course be present at the repository level during the initial construction phase. After sealing the repository, this oxygen will be consumed by reactions with minerals, by microbial activity and by corroding the copper containers. At the time when dissolved sulfide will reach the containers, they will be covered by corrosion products from the initial construction phase. These corrosion products may include cuprite $\left(\mathrm{Cu}_{2} \mathrm{O}\right)$, tenorite $(\mathrm{CuO})$, and, due to the high chloride content in the deep groundwaters at the Swedish and Finnish repository sites in the fennoscandian shield, paratacamite (a polymorph of copper hydroxychloride with the chemical formula $\left.\mathrm{Cu}_{2} \mathrm{Cl}(\mathrm{OH})_{3}\right)$. In the presence of increased carbonate concentrations, malachite (a copper carbonate hydroxide with the chemical formula $\mathrm{Cu}_{2} \mathrm{CO}_{3}(\mathrm{OH})_{2}$ ) may also form.

$\mathrm{X}$-ray spectroscopy ${ }^{2-4}$ and X-ray photoelectron spectroscopy ${ }^{5-8}$ have given strong evidence that copper is monovalent in all copper sulfides. The copper corrosion products that are formed during the aerobic phase of the repository will, on the other hand, most likely be divalent copper compounds. Therefore, $\mathrm{Cu}$ (II) is reduced to $\mathrm{Cu}(\mathrm{I})$ during the reactions with the sulfide ions. The mechanisms for the reduction are, however, not known in detail. Galtayries and Bonnelle ${ }^{9}$ studied the gas phase interaction between $\mathrm{H}_{2} \mathrm{~S}$ and $\mathrm{Cu}, \mathrm{Cu}_{2} \mathrm{O}$ and $\mathrm{CuO}$ surfaces with $\mathrm{X}$-ray photoelectron spectroscopy and ion scattering spectroscopy. They found that the $\mathrm{Cu}^{2+}$ species were reduced to $\mathrm{Cu}^{+}$ and that adsorbed $\mathrm{S}^{2-}$ was oxidized to sulfate-like species. Barbour et al. ${ }^{10}$ found no visible or measurable sign of sulfidation in $\mathrm{CuO}$ samples that had been exposed for 5.5 hours at $24^{\circ} \mathrm{C}$ in $65 \%$ humidity air containing $600 \mathrm{ppb} \mathrm{H}_{2} \mathrm{~S}$. In the studies of sulfidation of copper oxides in water solutions, Hollmark et al. ${ }^{3,4}$ did not find that $\mathrm{CuO}$ was

${ }^{\text {z} E-m a i l: ~ l a u r e n t . d u d a @ p h y s i c s . u u . s e ~}$ markedly more resistant to sulfidation than $\mathrm{Cu}_{2} \mathrm{O}$. They did not attempt to determine the sulfidation rate, but the exposure time they used did not produce any noticeable difference between the two oxides. This may indicate that the oxides are sulfidized by similar mechanisms. They observed, however, that prolonged exposure to the synchrotron beam of $\mathrm{CuO}$ formed electrochemically on a $\mathrm{Cu}$ coupon appeared to reduce $\mathrm{Cu}^{2+}$ contribution in the X-ray absorption spectrum. ${ }^{4} \mathrm{~A}$ likely reason for this could be a radiation induced comproportionation reaction:

$$
\mathrm{Cu}^{2+}+\mathrm{Cu} \rightarrow 2 \mathrm{Cu}^{+}
$$

This observation raised the issue of the comproportionation reaction also taking part in the sulfidation reaction so that $\mathrm{Cu}$ acted as an electron donor for the reduction of $\mathrm{Cu}^{2+}$ rather than the sulfide as proposed by Galtayries and Bonnelle ${ }^{9}$ for the gas phase reaction. The purpose of the present study is to test if there is a difference in the resistance to sulfidation if the potential corrosion product has grown on a copper substrate or if it is present without metallic copper, i.e. as a powder. The potential corrosion products tenorite (cupric oxide, $\mathrm{CuO}$ ), paratacamite and malachite were targeted for this investigation. Due to the quite saline deep groundwaters, paratacamite is perhaps most likely to form and has also been identified in experiments mimicking the conditions in a Swedish nuclear waste repository during the aerobic phase. $^{11}$

We find that exposure of oxidized copper cover layers to an aqueous sulfide solution effectively converts the top $\sim 100 \mathrm{~nm}$ layer to one dominated by copper sulfide with high sulfur content. By contrast, the powders of the corresponding single-phase oxides exposed to sulfide solution show much less chemical change. This suggests that the underlying $\mathrm{Cu}$ plays an important role for the transformation of its native oxides and possible mechanisms are discussed. Furthermore, the reaction of the sulfide solution with the copper oxide copper cover layers leads to the precipitation of a solid around the sample as a halo. The chemistry of the precipitate is analyzed as consisting foremost of $\mathrm{Cu}(\mathrm{I})$ species.

\section{Experimental}

Synthetization of single-phase copper oxides.- Our goal was to synthesize cover layers that mimic natural oxides that can form on the copper lining of a canister, i.e. tenorite, paratacamite or malachite. For this purpose, various corrosion mechanisms were applied to $\mathrm{Cu}$ 


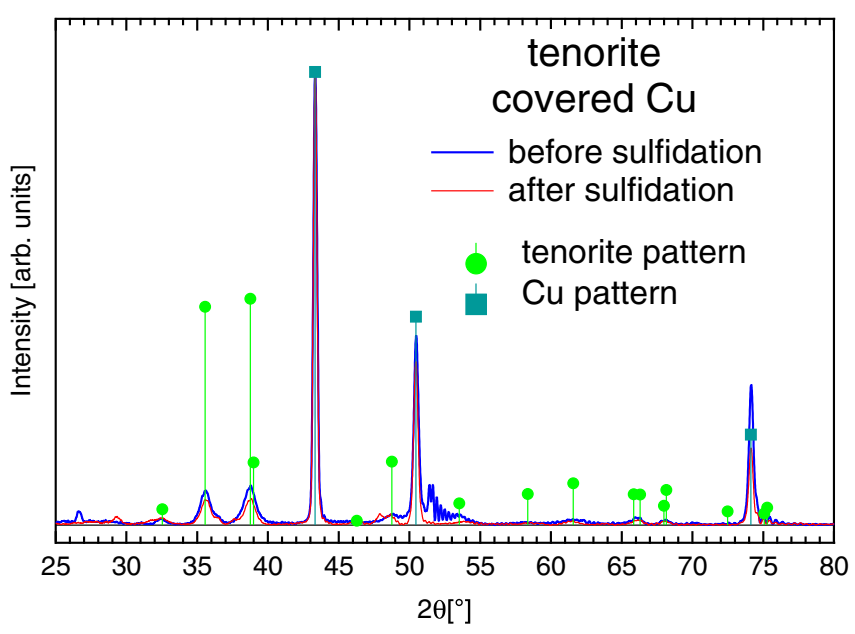

Figure 1. X-ray diffractograms of tenorite covered copper metal before (blue traces) and after (red traces) sulfidation. While the peaks of the metallic copper substrate (squares, PDF No. 00-004-0836) dominate the spectrum, the strongest tenorite peaks (circles, PDF No. 01-072-0629) confirm the growth of the desired oxide layer.

substrates, each yielding a different specific compound. Coupons of copper gaskets (normally used for sealing flanges of vacuum chambers) were used as substrates. The material consisted of $99.99 \% \mathrm{C} 101$ grade oxygen-free electronic (Cu-OFE) copper with less than $5 \mathrm{ppm}$ oxygen content. Pieces $\left(1 \times 1 \mathrm{~cm}^{2}\right)$ were cut from the gaskets, cleaned for 10 minutes in a $10 \% \mathrm{H}_{2} \mathrm{SO}_{4}$ solution, and then corroded. In order to produce the desired single-phase cover layer oxides of tenorite, paratacamite or malachite we followed the procedures described by Merkel $^{12}$ and the references therein, as summarized below. We also synthesized powders of paratacamite and malachite in $300 \mathrm{~mL}$ beakers containing aqueous solutions, as described below.

Tenorite preparation.-Pure copper substrates were placed in $40 \mathrm{~mL}$ of a solution of $0.57 \mathrm{M} \mathrm{KClO}_{3}$ and $0.1 \mathrm{M} \mathrm{Na}_{2} \mathrm{CO}_{3}$ at a temperature of $50^{\circ} \mathrm{C}$. A solid black cover layer developed after three days. X-ray diffraction (XRD) confirmed it to be $\mathrm{CuO}$, see Fig. 1 .

Paratacamite preparation.-1) Pure copper substrates were placed in $40 \mathrm{~mL}$ of a solution of $16.5 \mathrm{mM} \mathrm{NaCl}$ and $4 \mathrm{mM} \mathrm{NaNO}$. The $\mathrm{pH}$ was adjusted to 2 using concentrated $\mathrm{HCl}$. After 24 days enough paratacamite had formed to allow confirmation with XRD, see Fig. 2 (top).

2) $150 \mathrm{~mL} 0.5 \mathrm{M} \mathrm{NaOH}$ was mixed with the same volume of 0.5 $\mathrm{M} \mathrm{CuCl}_{2}$ at $25^{\circ} \mathrm{C}$ and stirred for about $30 \mathrm{~s} .{ }^{13}$ The solid powder that formed was separated from the solution by vacuum filtration. X-ray diffraction confirmed that the product was paratacamite, see Fig. 2 (bottom).

Malachite preparation.-1) Two different methods were attempted for producing malachite on pure $\mathrm{Cu}$ metal. The method described by Merkel $^{12}$ was used first. Pure copper substrates were initially placed in a beaker filled with $3 \mathrm{mM} \mathrm{Na} \mathrm{CO}_{3}$ solution. The beaker was open to air and bubbled with $\mathrm{CO}_{2}$ for 10 minutes every day to keep the solution saturated. However, instead of the expected blue-green corrosion product, only a steel gray cover layer was observed. For the second method a $1 \mathrm{M} \mathrm{Na}_{2} \mathrm{CO}_{3}$ solution was used and a small amount of copper filings added. In this case, the copper substrates became covered with a dark green product that appeared brownish-green when dried. The XRD Fig. 3 (top), however, did not confirm the oxide to be malachite as intended. Instead, the oxide cover layer was found to be most likely cuprite. Later, the X-ray absorption spectra corroborated this identification and thus the samples have been regarded as cuprite samples rather than malachite.

2) $150 \mathrm{~mL} 0.1 \mathrm{M} \mathrm{Cu}\left(\mathrm{NO}_{3}\right)_{2}$ was mixed with the same volume of $0.1 \mathrm{M} \mathrm{Na}_{2} \mathrm{CO}_{3}$ at $50^{\circ} \mathrm{C}$ and stirred for about $30 \mathrm{~s}^{14}$ The solid powder that formed was separated from the solution by vacuum filtration. $\mathrm{X}$ -

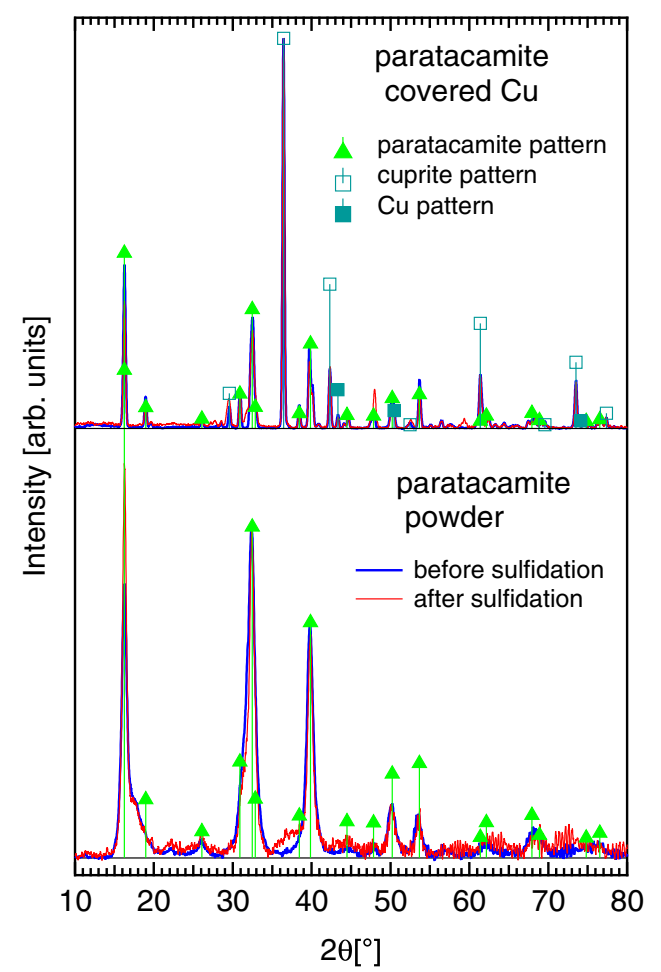

Figure 2. X-ray diffractograms of the samples prepared by using paratacamite synthesis before (blue traces) and after (red traces) sulfidation. The XRD of the paratacamite covered copper metal (top) shows peaks from paratacamite oxide (PDF No. 01-087-0679), metallic copper and cuprite (PDF No. 00-0050667). The XRD from the paratacamite powder shows a very pure paratacamite pattern where its ten strongest peaks are clearly present.

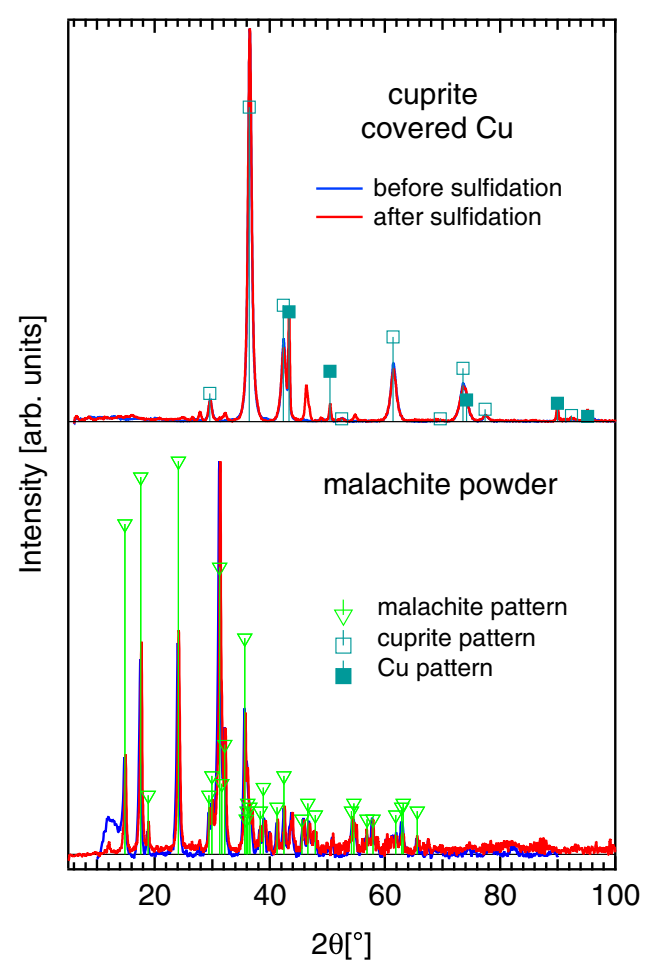

Figure 3. X-ray diffractograms of the samples prepared by using malachite synthesis before (blue traces) and after (red traces) sulfidation. The XRD of the oxide powder (bottom) shows a very pure malachite pattern (PDF No. 00-041-1390), whereas the XRD of the oxide coated copper metal (top) shows only peaks from cuprite and $\mathrm{Cu}$ metal patterns. 
ray diffraction confirmed that the product was malachite, see Fig. 3 (bottom).

Sulfidation of the prepared oxides.- For the sulfide treatment, a solution of $1 \mathrm{mM} \mathrm{Na}{ }_{2} \mathrm{~S}$ and $0.1 \mathrm{M} \mathrm{NaCl}$ was used, leading to a very alkaline environment with a $\mathrm{pH}$-value of about 11 . In order to reduce the oxygen content of the distilled water, it was kept at $60^{\circ} \mathrm{C}$ and bubbled with pure helium for 1 hour before preparing the solution. The oxidized copper samples were exposed in $40 \mathrm{~mL}$ of the sulfide solution for 5 hours. The powder samples were stirred constantly to ensure that all powder particles came in contact with the sulfide solution. In order to minimize oxygenation of the solution, a constant flow of argon was maintained into the beakers during the process. The oxidized copper samples changed their color into a deeper black in about 30 minutes and a yellowish brown halo precipitated around the sample in the beaker glass (see section Results-Halo formation during sulfidation of oxidized $\mathrm{Cu}$ ). The powdered samples changed from green to dark gray in a matter of seconds. After 30 minutes, the remaining powder was retrieved from the solution by running it through a filter paper. After drying, the retrieved powder, which was less in amount than the reactant powder initially added to the solution, appeared to have regained a greenish color similar to the ingoing reactant powder.

$X$-ray diffraction. - X-ray diffractograms were recorded using two different Siemens D5000 diffractometers with $\mathrm{Cu} \mathrm{K}_{\alpha}$ radiation. For the oxidized copped samples, a grazing incidence parallel beam was chosen, while a Bragg-Brentano setup with a locked coupled scanning mode was used for the powder samples. Figures 1 to 3 show the measured intensities $I$ at all angles $2 \theta$ between the X-ray source and detector. The data have been processed using different tools

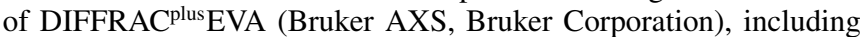
background subtraction, $\mathrm{K}_{\alpha 2}$-stripping and data smoothing. It was also used for finding matches from the International Centre for Diffraction Data (ICDD) powder diffraction database. The powdered samples were ground finely in a mortar and suspended in ethanol and spread onto a silicon wafer, leaving a layer of the powdered sample after the ethanol had evaporated. We find that sulfidation affects the XRD only marginally. This means that sulfidation of the material does not reach the bulk of the material, be it powder or oxidation layer. However, below we will show that outer layers (some 100 nanometers) of the oxides may indeed be transformed by sulfidation and that the result depends on whether the oxide is grown on $\mathrm{Cu}$ metal or as a single-phase powder.

$X$-ray spectroscopy. - The measurements were performed at beamline U41-PGM ${ }^{15}$ of BESSY II at Helmholtz-Zentrum Berlin (HZB), Germany. This is an undulator beamline delivering a flux density to the sample of $\sim 10^{12}-10^{13}$ photons/s in the excitation energy interval 170 - $1500 \mathrm{eV}$. All samples were investigated with both X-ray absorption spectroscopy (XAS), by means of simultaneously recording total fluorescence yield (TFY) and total electron yield (TEY), and resonant inelastic X-ray scattering (RIXS) at the $\mathrm{Cu} \mathrm{L}_{3,2}$-edge using an energy spread of $0.3 \mathrm{eV}$ (full width at half maximum) of the incident $\mathrm{x}$-rays. While TFY and TEY both reflect the empty density of states just above the Fermi level they are complementary with respect to the information depth. TEY is measured as the current to the sample that compensates the electrons that have sufficient energy to escape from the sample surface into the UHV chamber. Generally, this has shown to result in an information depth of about $10 \mathrm{~nm}^{16}$ for oxide solids. TFY is measured by an X-ray sensitive photodiode (AXUV100EUT, IRD, Inc.) while background light in the visible wavelength range is avoided by making all window ports of the vacuum chamber light tight. The photons escaping from the sample have about the same penetration depth as the incoming $\mathrm{x}$-rays, i.e. of about $100 \mathrm{~nm}$ below the surface, thus rendering TFY a bulk sensitive technique (for homogeneous samples).

Core electron excitation in XAS is also the first step of RIXS, in which the core hole is refilled typically by a valence electron. RIXS reflects electronic excitations in the IR- to optical-energy range that
Table I. Position of salient peaks in the Cu L XAS spectra.

\begin{tabular}{ccc} 
Label & Position & Origin \\
\hline (A) & $931.2 \mathrm{eV}$ & paratacamite, $\mathrm{Cu}$ (II)-oxide \\
$(\mathrm{B})$ & $931.7 \mathrm{eV}$ & tenorite, $\mathrm{Cu}$ (II)-oxide \\
$(\mathrm{C})$ & $932.6 \mathrm{eV}$ & $\mathrm{Cu}$ (I)-sulfide \\
(D) & $934.2 \mathrm{eV}$ & $\mathrm{Cu}_{2} \mathrm{O}, \mathrm{Cu}$ (I)-oxide
\end{tabular}

are site- and configuration-selected by the choice of incident energy. Thus RIXS is capable of revealing more detailed chemical information about the system, for instance by checking the occurence of crystal field excitations in $\mathrm{Cu}$ L-RIXS (see below). Since RIXS is a photononly experiment, it has a low surface sensitivity with an average probing depth of some $100 \mathrm{~nm}$. RIXS spectra were obtained by a home laboratory built grazing incidence Rowland spectrometer ${ }^{17}$ with a resolution of $0.5 \mathrm{eV}$ by collecting spectra of third order diffraction from a $1200 \mathrm{l} / \mathrm{mm}$ spherical grating with a $5 \mathrm{~m}$ radius of curvature.

\section{Results}

Oxidized copper metal.- Figure 4 shows the $\mathrm{Cu} 2 \mathrm{p}$ X-ray absorption spectra from $\mathrm{Cu}$ samples prepared according to the above oxidation procedure for tenorite, paratacamite, and malachite (I) before (left panel, top) and (II) after (left panel, bottom) exposure to the sulfide solution. Spectra from reference samples are provided in the right panel of Fig. 4 for comparison. XAS spectra (using blue and red traces) from $\mathrm{Cu}$ metal and cuprite, as well as $\mathrm{CuS}$ powder, and $\mathrm{Cu}_{2} \mathrm{~S}$ powder (Sigma Aldrich $99.99 \%$ ) have been recorded during the same beamtime while XAS spectra of cuprite, tenorite, and atacamite (using black traces) have been taken from literature. ${ }^{18}$ For convenience of comparing peak positions, four vertical dashed lines have been drawn across all three panels and they have been labeled (A)-(D) in the top panels. Table I lists the energy positions of these lines associated with peaks from different spectra.

The XAS spectra of the sample prepared to obtain a malachite layer on copper were very similar to those of cuprite instead of malachite as found in the literature, ${ }^{3,18}$ thereby confirming the earlier identification by XRD. Thus the sample appears to be covered with cuprite and is referred to as "cuprite covered" in the following, instead. In the case of tenorite and paratacamite cover layers, the TFY spectra are very similar to previously published TFY spectra of tenorite ${ }^{3,18}$ and atacamite (a polymorph of copper hydroxychloride besides to paratacamite). ${ }^{18}$ Also the TEY spectra are in very good agreement except that the TFY spectra have a broader low energy peak, which is probably due to saturation effects inherent to this technique.

The exposure to the sulfide solution completely altered the spectra of the initially prepared oxide cover layers on $\mathrm{Cu}$. In the case of tenorite and paratacamite cover layers (lower two spectra in the respective left panels of Fig. 4), their respective low-energy peaks (A) and (B) around $931 \mathrm{eV}$, which is a signature of $\mathrm{Cu}(\mathrm{II})$, is replaced by an absorption peak $(\mathrm{C})$ at higher photon energy $(932.5 \mathrm{eV})$, indicating the presence of $\mathrm{Cu}(\mathrm{I})$. Overall, the spectra of these two samples after sulfidation appear quite similar above (C) and their spectra closely resemble that of our reference sample $\mathrm{CuS}$ (blue traces in lower right panel of Fig. 4). In particular, the main peak position (C) at about 932.5 $\mathrm{eV}$ is very close to the energy of the absorption peaks of $\mathrm{CuS}$ and $\mathrm{Cu}_{1.8} \mathrm{~S}$ as reported in Ref. 20. Note that due to its bulk sensitivity, the TFY spectra reveal (by the additional spectral weight at $931 \mathrm{eV}$ ) that deeper layers may contain more oxygen than the outermost layers, so we estimate the sulfidized layer to be about 50-100 nm thick.

Fortuitously, the cuprite covered $\mathrm{Cu}$ offered a different starting point due to its $\mathrm{Cu}(\mathrm{I})$ oxide nature. Also in this case, sulfidation gives rise to strong changes of the spectral appearance. Close inspection of the XAS spectra after sulfidation reveals that the greatest resemblance can be found with the spectral shape of the TFY of the reference sample $\mathrm{Cu}_{2} \mathrm{~S}$ (red traces in lower right panel of Fig. 4). We attribute the lower energy onset (i.e. a "shoulder") of the reference spectrum 

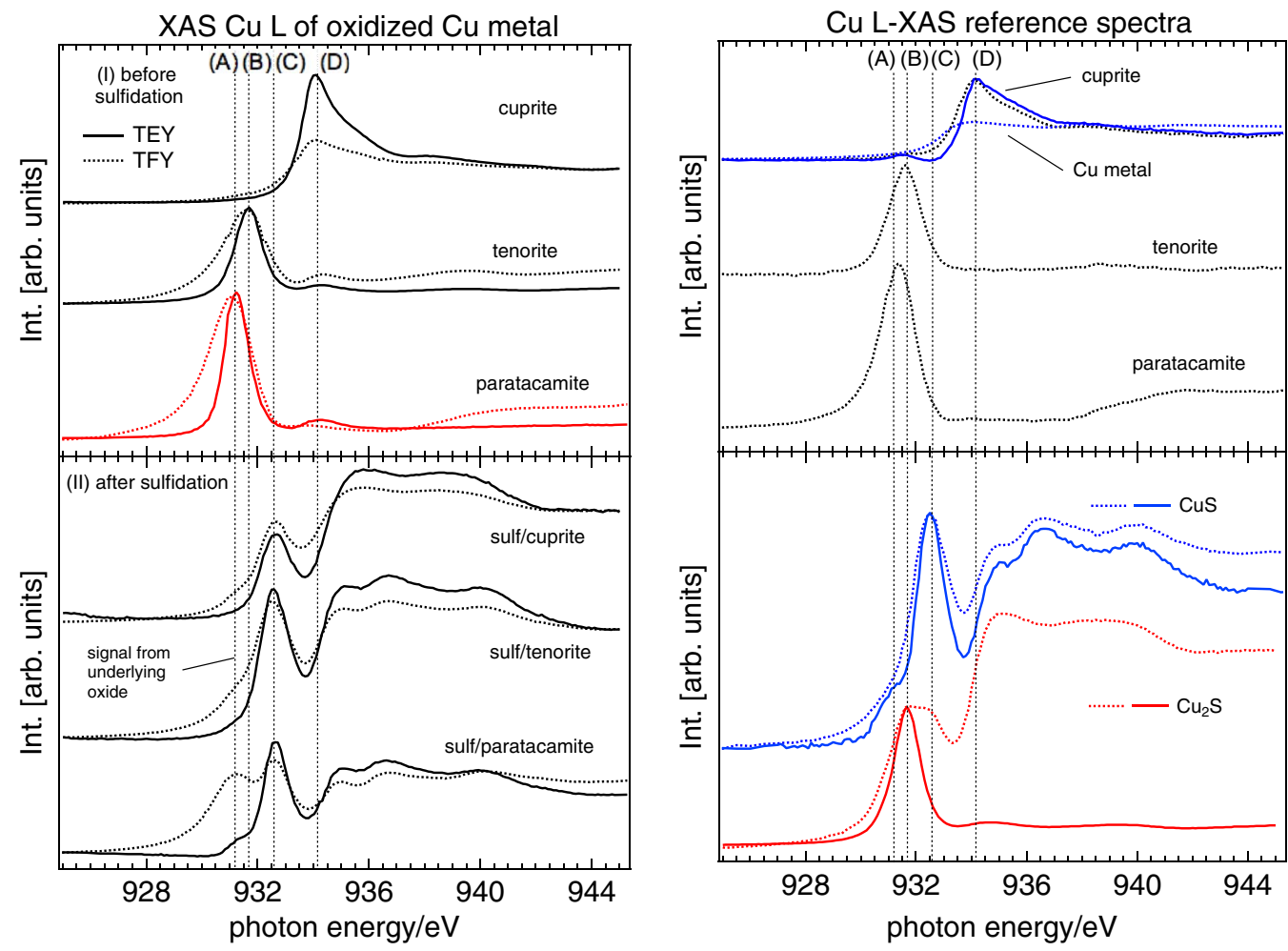

Figure 4. Left panel: $\mathrm{X}$-ray absorption spectra at the $\mathrm{Cu} \mathrm{L}_{3}$-edge from cuprite, tenorite, and paratacamite covered copper before sulfidation (top) and after sulfidation (bottom). Right panel: XAS spectra from reference compounds. The cuprite and $\mathrm{Cu}$ metal spectra (blue traces, top) are from the present experiment. The other $\mathrm{Cu}$-oxide spectra (top) are from Ref. 18 and the pure sulfide powder spectra are from Ref. 20. The vertical dashed lines (labeled (A)-(D)) are guides to the eye for peak energies as tabulated in Table I. The solid (dashed) traces in the panels are XAS spectra taken in TEY-mode (TFY-mode).

of $\mathrm{Cu}_{2} \mathrm{~S}$ to an artifact caused by its exposure to ambient air. The TEY of $\mathrm{Cu}_{2} \mathrm{~S}$, surface sensitivity even leads to a complete domination of this contribution. Thus the cuprite cover layer of $\mathrm{Cu}$ appears to be converted into a $\mathrm{Cu}(\mathrm{I})$ sulfide similar to $\mathrm{Cu}_{2} \mathrm{~S}$ but with a surface that appears more stable in ambient conditions (judging from the close resemblance of TFY and TEY of cuprite).

Powder oxide samples. - Figure 5 shows the XAS from the paratacamite and malachite powder samples (tenorite powder was not available to us). The XAS spectra are characterized by a strong low energy peak $\left(\mathrm{Cu} 2 \mathrm{p}^{6} 3 \mathrm{~d}^{9}-\mathrm{Cu} 2 \mathrm{p}^{5} 3 \mathrm{~d}^{10}\right.$ transitions) and a weaker charge transfer (CT) satellite peak $\left(\mathrm{Cu} 2 \mathrm{p}^{6} 3 \mathrm{~d}^{10} \mathrm{~L}^{-1}-2 \mathrm{p}^{5} 3 \mathrm{~d}^{10} 4 \mathrm{~s}^{1} \mathrm{~L}^{-1}\right)$. Sulfidation does not seem to affect the spectral shapes, which suggests that copper oxides in powder form are more inert to the sulfide solution than oxide grown on top of metallic copper. Note however, that similar looking XAS spectra can belong to different compounds in some cases, and therefore we turned to RIXS that can give additional information.

Excitation at the main peak $(931 \mathrm{eV})$ confirmed the transformation of the oxide cover layer of $\mathrm{Cu}$ whereas the oxide powders had similar RIXS spectra before and after sulfidation (not shown). However, some differences in the RIXS spectra for excitation at higher photon energies were found. Figure 6 shows RIXS spectra excited at $934 \mathrm{eV}$ from paratacamite, as cover layers and as powder, respectively. We note that in previous studies, ${ }^{18}$ RIXS excited at the XAS satellite structures of other $\mathrm{Cu}$ compounds has been shown to be a very sensitive tool to enhance the small differences of predominantly divalent $\mathrm{Cu}$ L-XAS spectra.

Note that the features belonging to elastic peak, monovalent $\mathrm{Cu}$, and divalent $\mathrm{Cu}$ are all present in the initial samples (blue traces) and appear at well-defined energy positions for both the cover layers and the powder. After exposure (red traces) the peak associated with monovalent $\mathrm{Cu}$ substantially gains in spectral weight despite the fact that the XAS spectra, RIXS spectra excited at the main peak, and the
XRD patterns of paratacamite powder do not show the same degree of sensitivity. Thus we find that the sulfidation leads to a complete conversion from divalent to monovalent $\mathrm{Cu}$ for the cover layers while the powder initially already contains more monovalent $\mathrm{Cu}$. Sulfidation of the powder is also seen to lead to a substantial increase of monovalent $\mathrm{Cu}$ but the signature for divalent $\mathrm{Cu}$ is still strong (as expected from the XAS). We recall an analogous observation for heat-treated copper metal surfaces in our previous paper. ${ }^{3}$ Thus our RIXS corroborate the above observations that powder oxides are more inert to transformation from $\mathrm{Cu}$ (II) to $\mathrm{Cu}$ (I) by exposure to sulfide solution.

Halo formation during sulfidation of oxidized $\mathrm{Cu}$. - As mentioned above, we observed the formation of a halo on the bottom of the beaker around the samples during the sulfidation of the oxidized $\mathrm{Cu}$ samples. We assume that the halo are solid precipitates that form during the sulfidation process. A possible mechanism could be that sulfidation leads to initial dissolution of the formed compounds in the aqueous vicinity of the surface that diffuse and conglomerate to larger particles, and finally, precipitation in the beaker within several millimeters of the copper metal piece. Given the low solubility of the $\mathrm{Cu}$-oxides, it is interesting to speculate whether space charge effects are involved in the process, considering the spreading distance of the precipitates within the observed time of formation.

In order to investigate this phenomenon, two paratacamite covered $\mathrm{Cu}$ metal samples were placed on glass substrates inside the beaker filled with sulfide solution according to the same procedure as the one given in Experimental section. After the formation of the halo, the sulfide solution was carefully removed without disturbing the halo structures on the substrates. The thus obtained samples were allowed to dry in air before insertion into the experimental vacuum chamber for performing X-ray spectroscopy.

Fig. 7 shows photographs (right, upper two panels) of the two dried halo-samples (from paratacamite-covered $\mathrm{Cu}$ metal) taken prior 


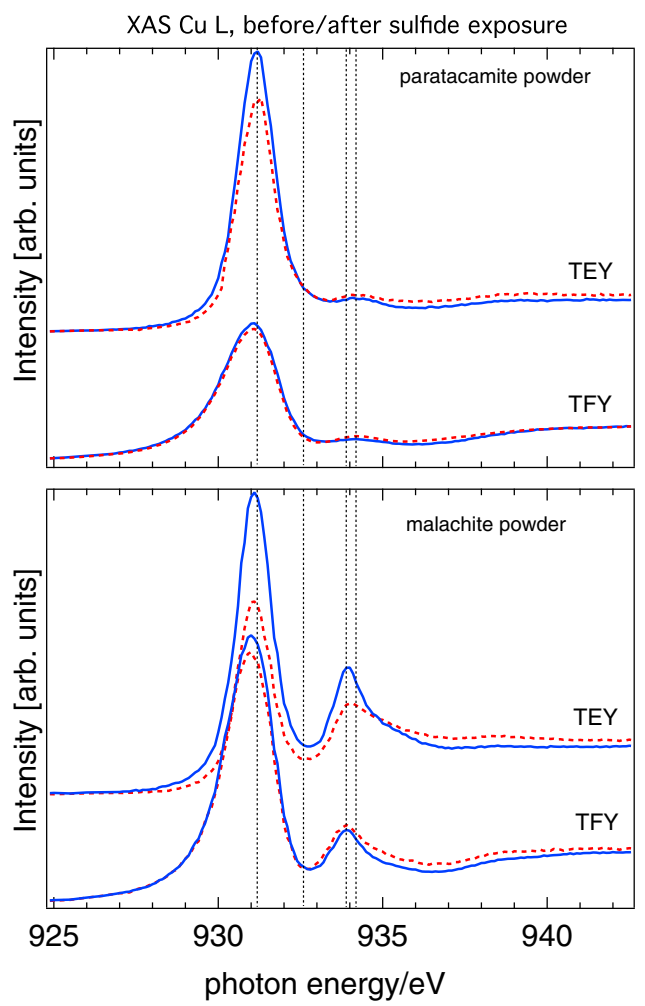

Figure 5. X-ray absorption spectra at the $\mathrm{Cu} \mathrm{L}_{3}$-edge (TFY- and TEY-mode as indicated) of paratacamite and malachite powder before and after sulfidation. Top panel: paratacamite powder sample. Bottom panel: malachite powder sample. Blue solid lines: before exposure. Red dashed lines: after exposure. Vertical dashed lines are guides to the eye.

to X-ray measurements. We identified certain regions by their visible color appearance as light orange, greenish, etc. (see below). The left panel of Fig. 7 displays TEY measurements on the halos at locations (I)-(IV) on sample A and sample B, respectively, as indicated in the photographs. Also, at the top of the left panel, we provide spectra (recorded at the same beamtime) from tenorite and cuprite samples serving as $\mathrm{Cu}(\mathrm{I})$ - and $\mathrm{Cu}(\mathrm{II})$-reference.

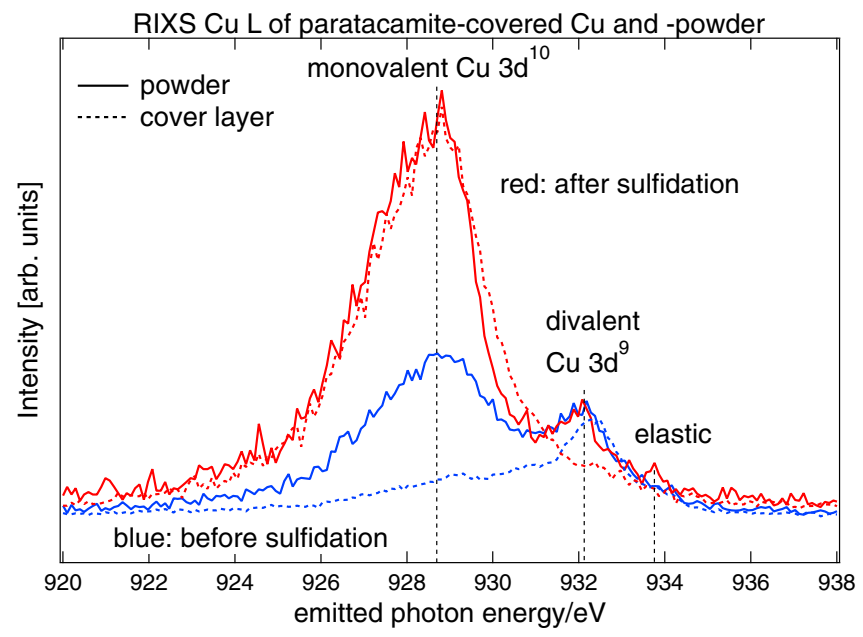

Figure 6. Comparison of RIXS spectra excited at the $\mathrm{Cu} \mathrm{L}_{3}$-edge from paratacamite covered copper (dashed lines) and paratacamite powder (solid lines). Blue lines: before sulfidation. Red lines: after sulfidation. The vertical dashed lines indicate the position of salient spectral features (elastic peak, divalent $\mathrm{Cu}$ peak, and monovalent $\mathrm{Cu}$ peak). See text for details.
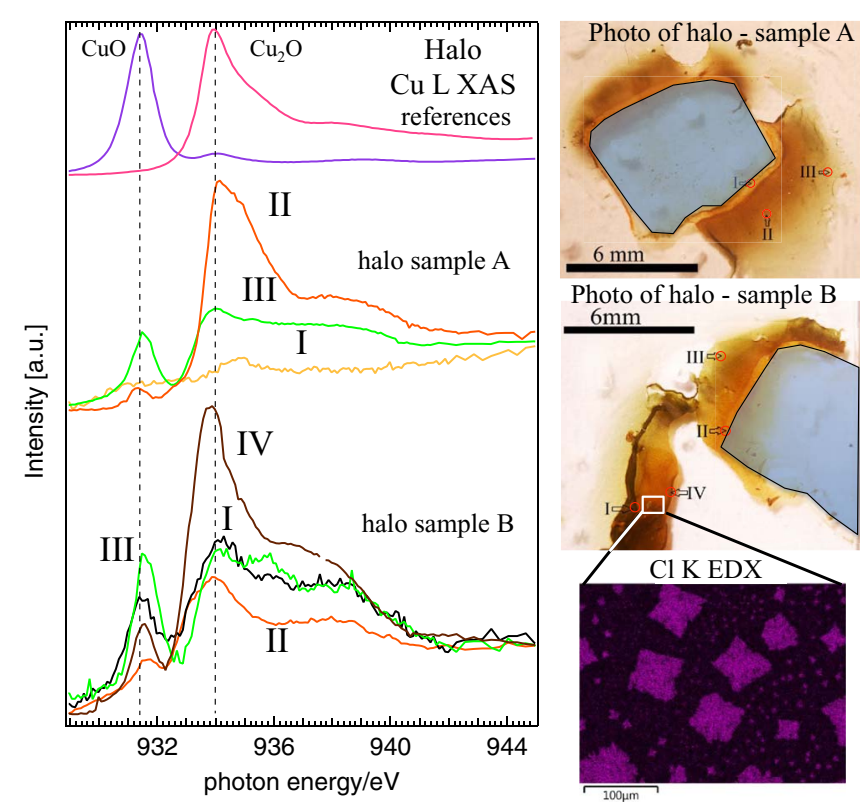

Figure 7. Left panel: $\mathrm{Cu}$ L-XAS from the halo precipate on two glass substrates from two paracatamite covered $\mathrm{Cu}$ samples $\mathrm{A}$ and $\mathrm{B}$ together with $\mathrm{Cu}(\mathrm{I})$ - and $\mathrm{Cu}(\mathrm{II})$-reference spectra. Top right panels: Photographs of the halo on the glass substrate. The original locations of the oxidized $\mathrm{Cu}$-samples are indicated by overlaid bluish polygons with black outline. The red circles and arrows next to the Roman numerals depict the location where the XAS measurements have been probing and correspond to the labeling of the spectra in the left panel. Lowest right panel: $\mathrm{Cl}$ K-edge energy dispersive X-ray (EDX) micrograph of sample B from an area between spot I and IV (square box).

\section{Sample A}

Spot I (light orange-colored areas): The overall signal is weak, probably because the halo layer is very thin here. The spectrum is broad and the second peak is located at higher energy than expected from the $\mathrm{Cu}(\mathrm{I})$-reference. This may indicate that the material possesses a mixture of oxidation states here.

Spot II (dark orange-colored areas): the $\mathrm{Cu}(\mathrm{I})$ peak is small compared to the $\mathrm{Cu}$ (II) peak, thus this area is of strong $\mathrm{Cu}$ (II) character. Note that the $937.8 \mathrm{eV}$ shoulder is more pronounced than that of the $\mathrm{Cu}(\mathrm{I})$ reference.

Spot III (greenish areas): here both $\mathrm{Cu}(\mathrm{I})$ and $\mathrm{Cu}(\mathrm{II})$ signatures are of similar intensity.

\section{Sample B}

Spot I (darkest areas): Both $\mathrm{Cu}(\mathrm{I})$ and $\mathrm{Cu}(\mathrm{II})$ signatures with a strong high energy shoulder, similar as spot III of sample A.

Spot II (orange-colored areas): Strong $\mathrm{Cu}(\mathrm{I})$ character.

Spot III (greenish areas): Very similar to spot III of sample A.

Spot IV (dark orange/brown-colored areas): Good signal to noise ratio (thick layer) and is predominantly $\mathrm{Cu}(\mathrm{I})$, similar to spot II of sample A.

In the lower right corner of Fig. 7 we provide a Cl K-edge EDX micrograph obtained in a region between spot I and IV of sample $\mathrm{B}$. We observe strong $\mathrm{Cl} \mathrm{K}$-signatures in roughly square areas on top of a background. This may indicate the formation of small $\mathrm{NaCl}$ crystallites at some point of the precipitation process. However, these are only remnant "footprints" and the crystallites themselves may well have been drained off in the removing and drying of the glass substrates that hold the halo precipitate.

\section{Discussion}

Comparing Fig. 4 and Fig. 5, we find that all oxidized copper samples transform more readily to $\mathrm{Cu}(\mathrm{I})$-species than the paratacamite and malachite powders exposed to aqueous sulfide solutions under 
identical conditions. We also note that, after sulfidation, oxidized copper samples, in contrast to the powder samples, showed a very low signal to noise ratio, in both the TEY- and the TFY-mode of O K XAS. Given the probing depths of these techniques, this indicates that the top layer down to $100 \mathrm{~nm}$ below the surfaces consists predominantly of oxygen-free $\mathrm{Cu}(\mathrm{I})$ compounds. Note that this does not rule out the re-formation of surface oxides in the first few atomic layers due to air exposure taking place between the sulfidation and the X-ray spectroscopy experiments. Our results can be compared to previously published studies of sulfidation of $\mathrm{Cu}$-oxide surfaces that had either been formed by thermally corroding $\mathrm{Cu}$ metal in $\mathrm{air}^{3}$ or that had been formed anodically. ${ }^{4}$ Subsequent sulfidation of these oxide surfaces performed at room temperature then led to a conversion of the oxide layers into a nearly equal mixture of $\mathrm{Cu}(\mathrm{I})$-oxide and -sulfide compounds, which stands in contrast to the much lower concentration of oxides that are probed in the present study. This difference is probably a consequence of the initially elevated temperature of our sulfide solution in the present case. For the sulfidation of all samples sulfide solutions with an initial temperature of $50^{\circ} \mathrm{C}$ (it had been heated to reduce the amount of dissolved oxygen) and then was left to gradual cool to room temperature while the sulfidation process was taking place. Considering the kinetic rule of thumb that a chemical reaction rate doubles for each $10^{\circ} \mathrm{C}$ temperature increase, ${ }^{19}$ this implies an increased reaction rate by a factor of 4 to 8 , in the present case. For the sulfidation of the oxidized-copper samples, the present study is representative of later stages than observed in previous experiments using sulfide solutions at room temperature, when the oxide content in the probed volume is still high.

In summary, the sulfide exposure can be described as transforming $\mathrm{Cu}$-oxide cover layers in several steps. An earlier one being the production of both $\mathrm{Cu}(\mathrm{I})$ oxides and sulfides. ${ }^{3,4}$ In the present study, we observe a later stage where most of the probed cover layer consists of pure $\mathrm{Cu}$-sulfide. While cuprite $\left(\mathrm{Cu}_{2} \mathrm{O}\right)$ covered $\mathrm{Cu}$ metal is found to transform into $\mathrm{Cu}_{2} \mathrm{~S}$, tenorite and paratacamite appear to transform into sulfides with higher sulfur content $(\mathrm{CuS})$. We note, however, that these observations concern the soft X-ray probing depth of about 100 nm. Our XRD measurements do not show appreciable differences before and after sulfidation, indicating that the prepared oxide layer must be much thicker, leaving the question open of whether or not longer sulfide exposure would continue to transform deeper layers.

For cuprite, where the oxidation state of copper is +1 , the sulfidation (assuming that our alkaline sulfide solution can be well described using $\mathrm{HS}^{-}$ions) can take place as a simple chemical conversion process, as Smith et al. ${ }^{21}$ suggests:

$$
\mathrm{Cu}_{2} \mathrm{O}+\mathrm{HS}^{-} \rightarrow 2 \mathrm{Cu}_{2} \mathrm{~S}+\mathrm{OH}^{-}
$$

As also stated by Smith et al., this scheme may be simplified, since the same final result could be achieved through two coupled galvanic reactions, reduction of $\mathrm{Cu}_{2} \mathrm{O}$ to $\mathrm{Cu}$ and oxidation of $\mathrm{Cu}$ to $\mathrm{Cu}_{2} \mathrm{~S}$ :

$$
\mathrm{Cu}_{2} \mathrm{O}+2 \mathrm{e}^{-}+\mathrm{H}_{2} \mathrm{O} \rightarrow 2 \mathrm{Cu}+2 \mathrm{OH}^{-}
$$

$$
2 \mathrm{Cu}+\mathrm{HS}^{-} \rightarrow \mathrm{Cu}_{2} \mathrm{~S}+\mathrm{H}^{+}+2 \mathrm{e}^{-}
$$

For sulfidation of $\mathrm{CuO}, \mathrm{Cu}$ (II) must be reduced to $\mathrm{Cu}$ (I). In Hollmark et $\mathrm{al}^{4}{ }^{4}$, the X-ray absorption spectrum could be deconvoluted into a contribution from $\mathrm{Cu}_{2} \mathrm{~S}$ and a contribution from $\mathrm{Cu}_{2} \mathrm{O}$. Even though a reaction similar to Equation 3 could be written for $\mathrm{CuO}$ and coupled with Equation 4 the presence of $\mathrm{Cu}_{2} \mathrm{O}$ on the sample surface reported in Ref. 4 indicates that a comproportionation reaction may take place:

$$
\mathrm{CuO}+\mathrm{Cu} \rightarrow \mathrm{Cu}_{2} \mathrm{O}
$$

$\mathrm{Cu}(0)$ may be the result of a concurrent reaction similar to Equation 3 or, perhaps more likely, the metallic copper underlying the oxides participate in the comproportionation by a solid state diffusion process through the oxide film. ${ }^{22}$

In the present study, tenorite and paratacamite cover layers of copper was rapidly sulfidized. The sulfidation of the paratacamite powder sample progressed much slower, but the RIXS spectra clearly indicated that the sample reacted with the sulfide solution. Another possible manifestation of sulfidation was the change in powder color when exposed to the sulfide solution.

The comproportionation reaction:

$$
\mathrm{Cu}^{2+}+\mathrm{Cu} \rightarrow 2 \mathrm{Cu}^{+}
$$

has an equilibrium constant $\mathrm{K}^{\circ}=10^{-5.79} .{ }^{23}$ That is, $\mathrm{Cu}^{+}$is only stable in solution at very low concentrations. The solubility products for the various copper sulfides are extremely small and the $\mathrm{Cu}^{+}$activity in $1 \mathrm{mM} \mathrm{Na} 2 \mathrm{~S}$ solution is, consequently, extremely low and the equilibrium of Equation 6 is strongly shifted to the right, resulting in destabilizing even relatively sparingly soluble $\mathrm{Cu}$ (II) compounds in the presence of $\mathrm{Cu}(0)$ and, therefore, facilitating the sulfidation process. The simplified net reaction could then be:

$$
2 \mathrm{Cu}^{+}+\mathrm{SH}^{-} \rightarrow \mathrm{Cu}_{2} \mathrm{~S}+\mathrm{H}^{+}
$$

For the paratacamite powder RIXS spectra were recorded, which confirm at least for this case that the absence of copper metal leads to a considerably slower, albeit not completely inhibited, reduction of the intitially present $\mathrm{Cu}(\mathrm{II})$-species.

It is possible that the mechanism proposed by Galtayries and Bonnelle $^{9}$ also contributes to the sulfidation process and is the dominant mechanism in the absence of metallic copper. The $\mathrm{Cu} \mathrm{S} \mathrm{S}_{3,2}$-edge absorption edge $(170 \mathrm{eV})$ is just at the limit of the energy range of the light source and no spectra could, therefore, be recorded. On the other hand, no $\mathrm{O} \mathrm{K}$-edge signal was detected on the sulfidized samples and if sulfate-like species had formed they must have dissolved into the liquid phase during the sulfidation.

A noteworthy form of corrosion of the oxidized copper exposed to sulfide solution is the observation of a copper oxide precipitate (as a halo). Though the mechanism and process is not yet fully understood, the mixture of $\mathrm{Cu}$-oxidation states that is present in the powder suggests that it consists of particles that have emerged from the surface at an earlier corrosion stage, similar as the ones observed in References 3 and 4. Evidence from EDX-microscopy for formation of $\mathrm{NaCl}$ shows that the halo is heterogeneous consisting of a phase mixture originating from oxide moeties in the $\mathrm{Cu}$-oxide cover layers.

\section{Conclusions}

We find that single-phase oxide cover layers of copper (e.g. tenorite and paratacamite) exposed to an aqueous sulfide solution are converted to ones dominated by copper sulfides with high sulfur content. Singlephase oxide powders do not show the same propensity of undergoing this type of reaction. Thus our study strongly suggests that the main mechanism for reduction of $\mathrm{Cu}$ (II) on copper is the comproportionation reaction between divalent copper ions from the cover-layer oxide and the underlying metallic copper atoms to form monovalent copper ions. Furthermore, the reaction of the sulfide solution with the copper oxide cover layers leads to the precipitation of non-metallic copper compounds, mainly consisting of $\mathrm{Cu}(\mathrm{I})$ species as well as and other oxide constituents, around the sample. The formation of such a halo precipitate with strong $\mathrm{Cu}(\mathrm{I})$-signature shows that sulfidation involves considerable mass transport away from the oxide cover layers of copper. Both results are of high relevance for the deposition of copper canisters in anoxic saline sulfide-containing groundwater.

\section{Acknowledgments}

We thank HZB for the allocation of synchrotron radiation beamtime and gratefully acknowledge technical support of the staff at beamline U41-PGM ${ }^{15}$ of BESSY II. This study was financially supported by the Swedish Nuclear Fuel and Waste Management Co (SKB).

\section{References}

1. Allan Hedin, Technical Report TR-10-66, Swedish Nuclear Fuel and Waste Management Co, Box 250, SE-101 24 Stockholm, (2010) 
2. H. M. Hollmark, P. G. Keech, J. R. Vegelius, P. Kristiansen, L. Werme, and L.-C. Duda, MRS Proceedings, 1475, 0 (2012).

3. Håkan Hollmark, Johan Vegelius, Paw Kristiansen, Lars Werme, and Laurent Duda, Journal of the Electrochemical Society, 158(1), C1 (2011).

4. H. M. Hollmark, P. G. Keech, J. R. Vegelius, L. Werme, and L.-C. Duda, Corrosion Science, $\mathbf{5 4}(0), 85$ (2012).

5. J. C. W. Folmer and F. Jellinek, Journal of the Less Common Metals, 76(1-2), 153 (1980).

6. J. C. W. Folmer, F. Jellinek, and G. H. M. Calis, Journal of Solid State Chemistry, 72(1), 137 (1988)

7. Siew Wei Goh, Alan N. Buckley, and Robert N. Lamb, Minerals Engineering, 19(2), 204 (2006).

8. Siew Wei Goh, Alan N. Buckley, Robert N. Lamb, Richard A. Rosenberg, and Damian Moran, Geochimica et Cosmochimica Acta, 70(9), 2210 (2006).

9. A. Galtayries and J-P. Bonnelle, Surface and interface analysis, 23(3), 171 (1995)

10. J. Charles Barbour, Jeffrey W. Braithwaite, and Alan F. Wright, Nuclear Instruments and Methods in Physics Research Section B: Beam Interactions with Materials and Atoms, 175, 382 (2001).

11. Ola Karnland, Siv Olsson, Ann Dueck, Martin Birgersson, Ulf Nilsson, Tania Hernan-Håkansson, Karsten Pedersen, Sara Nilsson, Trygve E Eriksen, and Bo Rosborg, Technical Report TR-09-29, Swedish Nuclear Fuel and Waste Management Co, Box 250, SE-101 24 Stockholm, (2009).
12. T. H. Merkel, Universität Karlsruhe, (2003).

13. A. M. Pollard, R. G. Thomas, and P. A. Williams, Mineralogical Magazine, 53(373), 557 (1989).

14. H. Tanaka and M. Yamane, Journal of Thermal Analysis and Calorimetry, 38(4), 627 (1992).

15. C. H. Jung, F. Eggenstein, S. Hartlaub, R. Follath, J. S. Schmidt, F. Senf, M. R. Weiss, T. H. Zeschke, and W. Gudat, Nuclear Instruments and Methods in Physics Research Section A: Accelerators, Spectrometers, Detectors and Associated Equipment, 467, 485 (2001).

16. J. Stöhr, NEXAFS Spectroscopy, Springer, (2003)

17. J. Nordgren, G. Bray, S. Cramm, R. Nyholm, J-E. Rubensson, and N. Wassdahl, Review of Scientific Instruments, 60, 1690 (1989).

18. K. O. Kvashnina, S. M. Butorin, A. Modin, L. Werme, J. Nordgren, J.-H. Guo, and R. Berger, Physica B: Condensed Matter, 404(20), 3559 (2009).

19. Kenneth Connors, Chemical Kinetics, p. 14, VCH Publishers (1990).

20. M. Grioni, J. B. Goedkoop, R. Schoorl, F. M. F. De Groot, J. C. Fuggle, F. Schäfers, E. E. Koch, G. Rossi, J-M. Esteva, and R. C. Karnatak, Physical Review B, 39(3) $1541(1989)$

21. J. M. Smith, J. C. Wren, M. Odziemkowski, and D. W. Shoesmith, Journal of the Electrochemical Society, 154(8), C431 (2007).

22. J. Chen et al., Corrosion Science, 87, 233 (2014).

23. Mingshen Wang, Yu Zhang, and Mamoun Muhammed, Hydrometallurgy, 45(1), 53 (1997). 